Article

\title{
The Behavior of Arsenic during the Thermal and Chemical Decomposition of the Ammonium-Arsenic Jarosite
}

\author{
Mizraim Flores 1,2,*, Francisco Patiño ${ }^{3}$, Elia G. Palacios ${ }^{2}$, Iván Reyes 4,5, Martín Reyes ${ }^{6}$, \\ Victor H. Flores ${ }^{6}$, Julio C. Juárez ${ }^{6}$ and Thangarasu Pandiyan ${ }^{7}$ \\ 1 Área de Electromecánica Industrial, Universidad Tecnológica de Tulancingo, \\ 43642 Tulancingo-Hgo., México \\ 2 Departamento en Ingeniería en Metalurgia y Materiales, ESIQIE, IPN, UPALM, Zacatenco, 07738 México, \\ D.F., México; epalacios@ipn.mx \\ 3 Ingeniería en Energía, Universidad Politécnica Metropolitana de Hidalgo, Boulevard Acceso a Tolcayuca \\ 1009, Ex Hacienda San Javier, 43860 Tolcayuca, Hgo., México; franpac@terra.com.mx \\ 4 Instituto de Metalurgia, Universidad Autónoma de San Luis Potosí, 78210 San Luis Potosí-SL, México; \\ ivanalejandro2001@hotmail.com \\ 5 Consejo Nacional de Ciencia y Tecnologia (CONACYT), Colonia Crédito Constructor Del. Benito Juárez, \\ 03940 México-DF, México \\ 6 Área Académica de Ciencias de la Tierra y Materiales, UAEH, Carretera Pachuca-Tulancingo km 4.5, \\ 42184 Mineral de la Reforma, Hidalgo, México; mar_77_mx@yahoo.com.mx (M.R.), \\ vicelmaestro@hotmail.com (V.H.F.), jutj731101@hotmail.com (J.C.J.) \\ 7 Facultad de Química, UNAM, Ciudad Universitaria, 04510 México, D.F., México; pandiyan@unam.mx \\ * Correspondence: mflores@utec-tgo.edu.mx; Tel. +52-7711433711
}

\begin{abstract}
Arsenic, an element of environmental impact, can be incorporated into jarosite-type compounds and remain stabilised within the structure under a wide range of environmental conditions. In this study, a sample of ammonium-arsenic jarosite was synthesised by precipitation in sulphate medium at controlled $\mathrm{pH}$ of 1.2-1.8. The behaviour of arsenic during the thermal and chemical decomposition of jarosite was analysed; the degradation in alkaline medium of jarosite was also studied. According to the results, the synthesised jarosite is composed of joined rhombohedral crystals, forming tightly spherical shaped particles, 37-54 $\mu \mathrm{m}$ size. The ammonium jarosite produced possessed a high arsenic concentration; its calculated stoichiometry being $\left(\mathrm{NH}_{4}\right) \mathrm{Fe}_{2.45}\left[\left(\mathrm{SO}_{4}\right)_{1.80}\left(\mathrm{AsO}_{4}\right)_{0.20}\right]\left[(\mathrm{OH})_{4.15}\left(\mathrm{H}_{2} \mathrm{O}_{1.85}\right.\right.$. It was found that arsenic is stabilised in the jarosite structure; upon heating, it remains in residual solids above $700^{\circ} \mathrm{C}$, whilst in alkaline medium an incongruent dissolution takes place, with the arsenic retained in the solid phase along with iron. These solids, when exposed to high temperatures $\left(1200^{\circ} \mathrm{C}\right)$, transform into a type of iron oxide known as hematite, so with arsenic it is retained an iron compound forming a stable compound which withstands high temperatures.
\end{abstract}

Keywords: ammonium-arsenic jarosite; characterization; chemical decomposition and thermal decomposition

\section{Introduction}

In more than 70 countries, drinking water is polluted with arsenic. This is a public health problem affecting more than 150 million people worldwide [1,2,3]. One of its main causes is acid mine drainage (AMD), where arsenic is one of the metalloid contaminants, with concentrations that can reach up to hundreds of $\mathrm{mg} \mathrm{L}^{-1}$. This is the result of the oxidation of arsenic-rich sulphides, such as arsenopyrite and pyrite [2]. Several arsenic removal techniques have been developed, but they have not been entirely efficient due to the instability of the arsenic-containing residues [3]. 
Natural jarosite-type compounds are usually associated with minerals such as quartz, kaolinite, calcite, orthoclase, gypsum, goethite, hematite, shwermannite and amorphous Fe-oxides [4]. In the hydrometallurgical industry, inorganic compounds are used to eliminate impurities; for instance the synthesis of ammonium jarosite is widely used in zinc smelting to remove impurities such as $\mathrm{Fe}$; in the "jarosite process", ammonium and iron sulfates are added to the leach liquor to precipitate an ammonium jarosite. Due to their different coordination sites, jarosites have the capability to incorporate elements of environmental impact into their structure: substitutions in the cationic position $\left(\mathrm{Pb}^{2+}, \mathrm{Hg}^{2+}, \mathrm{Cd}^{2+}\right)$, or the substitution of sulphate $\left(\mathrm{SO}_{4}\right)^{2-}$ by arsenate $\left(\mathrm{AsO}_{4}\right)^{3-}$, phosphate $\left(\mathrm{PO}_{4}\right)^{3-}$ or chromate $\left(\mathrm{CrO}_{4}\right)^{2-}$ [5]. Dutrizac and Jambor and Dutrizac et al.; studied the behaviour of arsenic in jarosite-type compounds ( $\mathrm{Na}$ and $\mathrm{K}$ ), incorporating $4 \mathrm{wt} . \% \mathrm{AsO}_{4}{ }^{3-}$ in potassium jarosite and $1 \mathrm{wt} . \%$ in sodium jarosite [6,7]. Asta et al. studied the efficiency of jarosite, goethite and schwertmannite in absorbing arsenic from AMD, concluding that greater amounts of As were incorporated by potassium jarosite and schwertmannite [2]. Patiño et al. studied the decomposition kinetics in alkaline medium and subsequent cyanidation of jarosite-type compounds; they determined that the decomposition reaction is carried out in three stages; an induction period, a progressive conversion period and a stabilization zone [8-10].

In a recent study on the decomposition of an arsenic-containing jarosite compound in alkaline media [11,12], it was found that arsenic remained in the decomposition product, mainly as a constituent of amorphous iron hydroxide. There are few works on the dissolution and stability of such compounds, making the data insufficient for evaluating the real environmental risk caused by the improper disposal of the generated precipitates [13]. Ammonium jarosite may prove to be an alternative for the removal of arsenic contained in residual waters or in AMD; in both cases lime is added to the water, increasing the $\mathrm{pH}$ and favouring the precipitation and sedimentation of contaminant species, including arsenic [3]. Therefore, it is important to analyse the behaviour of the ammonium-arsenic jarosite in alkaline media. Besides, the hydrometallurgical industries, mainly the zinc industry use jarosite precipitation to control iron, sulfates and alkaline metals, amongst others. This generates a great amount of potentially dangerous residues, because upon their dissolution or decomposition, the arsenic might be released to the environment in bioavailable forms. Studies on the dissolution of natural and synthetic jarosites not containing arsenic had been carried out at different $\mathrm{pH}$ conditions. It has been found that those jarosites remained stable at highly acid and oxidizing conditions [14] and that dissolution is faster at alkaline $\mathrm{pH}$ than in acidic media; besides, it was observed than dissolution occurs in an erratic manner [12].

Therefore, in this article a study on the reactivity of an ammonium-arsenic jarosite is presented, with the aim to provide information regarding the stability of As in such a compound, at extreme conditions of alkaline $\mathrm{pH}$ and temperature. Accordingly, the thermal decomposition behaviour and the stoichiometry of the dissolution reaction in alkaline media of the synthetized jarosite was analysed in order to determine the effect on the liberation of arsenic from the solid residues. Thus, an ammonium-arsenic jarosite was synthesized to prevent interferences due to the presence of associated minerals. The results of this work will be the basis for future studies on the reactivity of jarosite-type compounds containing elements of environmental impact, either natural or of industrial origin. 


\section{Materials and Methods}

The sample of ammonium-arsenic jarosite was synthesised by a dissolution-precipitation technique, using ACS grade chemical reagents and deionised water. An aqueous solution with 0.25 $\mathrm{mol} \mathrm{L}^{-1} \mathrm{Fe}\left(\mathrm{SO}_{4}\right)_{3}, 0.30 \mathrm{~mol} \mathrm{~L}^{-1}\left(\mathrm{NH}_{4}\right)_{2} \mathrm{SO}_{4}, 0.03 \mathrm{~mol} \mathrm{~L}^{-1} \mathrm{As}_{2} \mathrm{O}_{4}$ and $0.01 \mathrm{~mol} \mathrm{~L}^{-1} \mathrm{H}_{2} \mathrm{SO}_{4}$ was prepared and placed in a glass reactor set on a hot plate stirrer (Barnstead Thermolyne Super-Nuova) at $\approx 95^{\circ} \mathrm{C}$ and pH of 1.2-1.8 (Orion 3 Star pH-meter equipped with a Thermo Ross Ultra Sure Flow pH electrode) and $500 \mathrm{~min}^{-1}$ during 24 hours in a reflux system. The resulting sample was rinsed several times with hot water $\left(70^{\circ} \mathrm{C}\right)$ to remove residual $\mathrm{SO}_{4}{ }^{2-}$ and $\mathrm{Fe}^{3+}$. Finally, the solids were dried at $65^{\circ} \mathrm{C}$ for 5 hours. The sample of ammonium-arsenic jarosite was characterised using X-ray diffraction (XRD, Siemens D-500, with $\mathrm{Cu}-\mathrm{K} \alpha$ radiation of $1.54052 \AA$, patterns were collected from 15 to $90^{\circ} 2 \theta$ with a step size of $0.02^{\circ}$ and a rate of $30 \mathrm{~s}$ per step), attenuated total reflectance fourier transform infrared spectroscopy (FTIR-ATR, Perkin Elmer FT-IR Frontier) and scanning electron microscopy with energy dispersive $\mathrm{X}$-ray spectroscopy (SEM-EDS, JEOL JSM-5900LV equipped with a thermo energy dispersive $X$-ray analyser using $15 \mathrm{kV}$ ). The chemical analyses were conducted by inductively coupled plasma optical emission spectroscopy (ICP-OES, Perkin Elmer Optima-3000XL) to determine $\mathrm{S}$, dichromatometry to determine Fe, atomic absorption spectroscopy (AAS, Perkin Elmer AAnalyst 200) to determine As and elemental analysis (Perkin Elmer CHN/SO2440) to determine N; ammonium was calculated by stoichiometry. An aliquot of the powder was dissolved in $\mathrm{HCl}(50 \%$ $\mathrm{v} / \mathrm{v}$ ) for the elemental analysis. The solution was kept at $70^{\circ} \mathrm{C}$ with mechanical stirring until no solids were observed. The dissolution was then made up to $100 \mathrm{~mL}$ in a volumetric flask; dissolutions and standards were prepared in identical matrices. Particle size was determined by means of the Tyler Equivalent (USA Standard Testing Sieve, ASTME-11 specifications) with the following mesh diameters: $125,90,75,53,45,38$ and $25 \mu \mathrm{m}$.

Thermal decomposition of the arsenic ammonium jarosite was carried out in a TGA 851e Mettler-Toledo thermogravimetric analyser, in a flowing air atmosphere $\left(666 \times 10^{-3} \mathrm{~m}^{3} \mathrm{~s}^{-1}\right)$ with a heating rate of $10^{\circ} \mathrm{C} \mathrm{min}^{-1}$ from room temperature to $1200^{\circ} \mathrm{C}$.

Decomposition of ammonium-arsenic jarosite was conducted in alkaline medium $(\mathrm{NaOH}, \mathrm{pH}$ 12.90 and $30^{\circ} \mathrm{C}$ for $\left.25 \mathrm{~min}\right)$. The decomposition solids were characterized by AAS, ICP, XRD and SEM-EDS. The decomposition solids were exposed to high temperatures $\left(400,700\right.$ and $\left.1100{ }^{\circ} \mathrm{C}\right)$ to observe their evolution towards new crystal phases. 


\section{Results and discussion}

\subsection{Synthesis and characterization}

Comparison between the XRD pattern obtained from the synthesized sample and the ICDD-PDF (International Center for Diffraction Data-Powder Diffraction Files) file confirms that the most intense peaks correspond to the structure of ammonium jarosite (Figure 1).

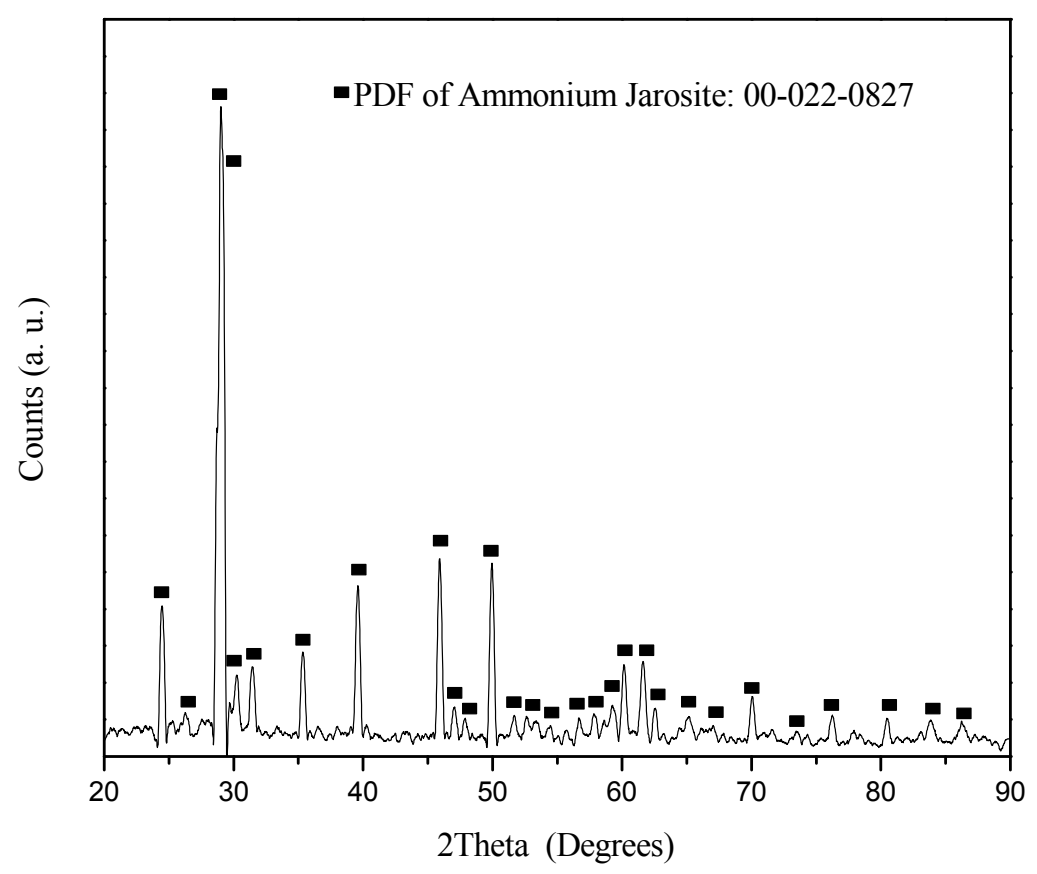

Figure. 1. X-ray diffraction pattern the synthesized sample compared to the ICDD-PDF of ammonium jarosite.

The synthesized product is a yellow coloured precipitate composed of particles in the range of 25-40 $\mu \mathrm{m}$ (Figure 2a). A semi-detailed image shows that most of the particles have a spherical tendency (Figure 2b). A detailed image of the particles shows that they are made of joined rhombohedral crystals forming a compact structure, with crystallite sizes ranging between 2 and 12 $\mu \mathrm{m}$ (Figure 2c). The EDS spectrum (Figure 2d) shows the typical peaks of the elements that form the ammonium-arsenic jarosite. Nitrogen does not appear due to an overlap with $\mathrm{O}$ and Fe. The gold signal on the spectrum is due to the coating implemented on the sample to make it conductor. 

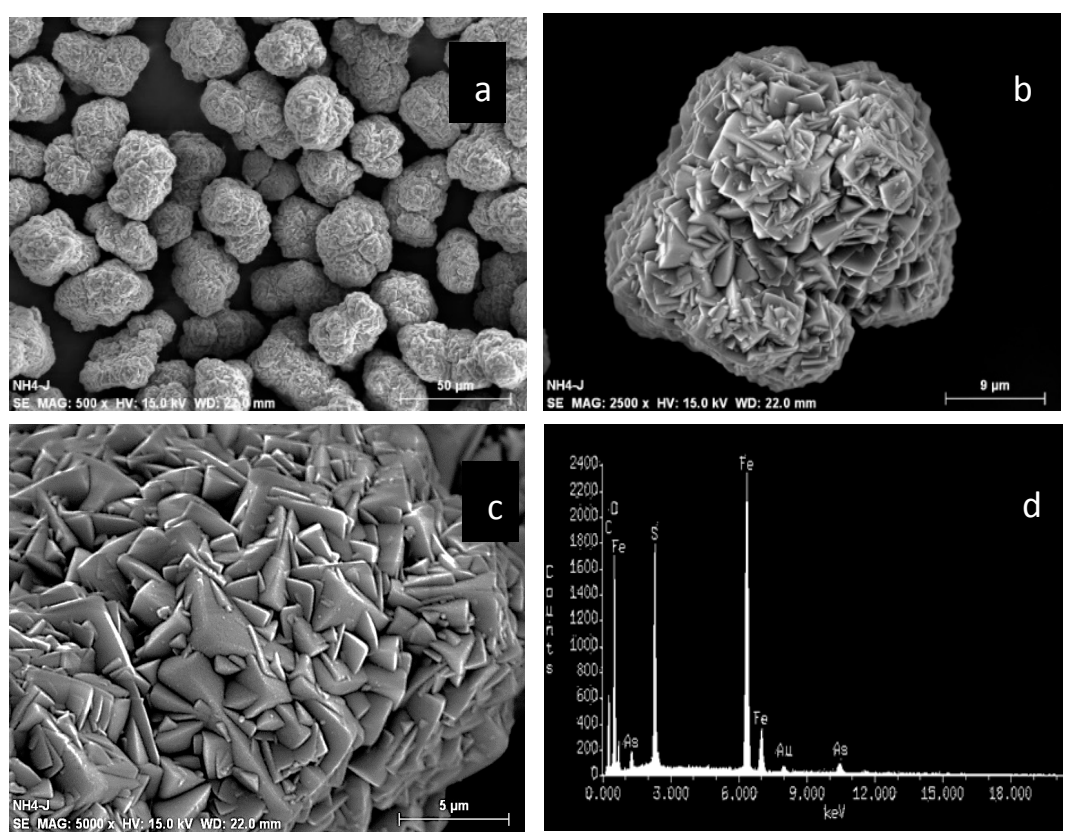

Figure 2. a) General image: particle size distribution of ammonium-arsenic jarosite. b) Semidetailed image of a particle with spherical tendency. c) Detailed image showing the microcrystals forming the particles. d) EDS of the particles of ammonium-arsenic jarosite.

Table 1 presents the chemical analysis results, indicating the presence of nitrogen and arsenic. The weight percentages of iron and sulfate present in the compound are similar to those reported by other authors $[6,7,12,13,15]$. However, the incorporation of arsenic in ammonium jarosite was higher than that reported by other authors for the synthesis of similar compounds, for example, reported an incorporation of $4 \mathrm{wt} . \%$ as $\mathrm{AsO}_{4}{ }^{3-}$ in potassium jarosite and $1 \mathrm{wt} . \%$ in sodium jarosite [6,7]. Patiño et al., (2013a) reported an incorporation of $4.1 \mathrm{wt} . \%$ as $\mathrm{AsO}_{4}{ }^{3-}$ in potassium jarosite. Reyes et al., (2011) reported an incoporation of $1 \mathrm{wt} . \%$ as $\mathrm{AsO}_{4}{ }^{3-}$ in a natrojarosite. Islas et al. (2013) reported an incorporation of $3.24 \mathrm{wt} . \%$ as $\mathrm{AsO}_{4}{ }^{3-}[11-13,15]$.

Table 1. Chemical composition of synthetic ammonium-arsenic jarosite.

\begin{tabular}{ccc}
\hline Species & Weight percentage & Analysis technique \\
\hline $\mathrm{Fe}$ & 28.63 & Dichromatometry \\
$\mathrm{As} / \mathrm{AsO}_{4}$ & $2.2 / 4.1$ & Atomic absorption spectroscopy \\
$\mathrm{SO}_{4}$ & 38.32 & Gravimetric analysis \\
$\mathrm{N} / \mathrm{NH}_{4}$ & $4.56 / 5.87$ & Elemental analysis \\
$\mathrm{OH}^{-}+\mathrm{H}_{3} \mathrm{O}^{+}+\mathrm{H}_{2} \mathrm{O}$ & 23.08 & Difference \\
\hline
\end{tabular}

Considering the molar relationships $\mathrm{NH}_{4}^{+}=1, \mathrm{SO}_{4}{ }^{2-}+\mathrm{AsO}_{4}{ }^{3-}=2, \mathrm{OH}^{-}+\mathrm{H}_{2} \mathrm{O}=6$, and taking into account that the difference between $\mathrm{SO}_{4}{ }^{2-}$ and $\mathrm{AsO}_{4} 4^{3-}$ is compensated by the conversion of $\mathrm{OH}^{-}$to $\mathrm{H}_{2} \mathrm{O}$, it is possible to calculate the approximate formula of the synthetic product as:

$\left(\mathrm{NH}_{4}\right) \mathrm{Fe}_{2.45}\left[\left(\mathrm{SO}_{4}\right)_{1.80}\left(\mathrm{AsO}_{4}\right)_{0.20}\right]\left[(\mathrm{OH})_{4.15}\left(\mathrm{H}_{2} \mathrm{O}\right)_{1.85}\right]$ 
The difference between theoretical and experimental compositions of synthetic ammonium-arsenic jarosite, according to the general formula $\mathrm{MFe}_{3}\left(\mathrm{SO}_{4}\right)_{2}(\mathrm{OH})_{6}$, is due to the fact that $\mathrm{SO}_{4}{ }^{2-}$ ions are substituted by $\mathrm{AsO}_{4}{ }^{3-}$ ions. As the amount of arsenic increases inside the crystal structure in jarosite type compounds, the primitive cell expands because the As-O bond (1.66-1.68 $\AA$ ) is longer than the S-O bond (-1.47 ̊) [16-18].

The density of ammonium-arsenic jarosite was determined with a picnometer, using distilled water as immersion liquid. The result was $2.72 \mathrm{~g} \mathrm{~cm}^{-3}$, which is similar to the values reported in previous studies on jarosite type compounds with arsenic $[11,13,15]$ and ammonium jarosite with silver [10], as shown on Table 2.

Table 2. Density and arsenic incorporation comparison between different jarosite type compounds.

\begin{tabular}{|c|c|c|}
\hline Jarosite type & wt. $\%$ of incorporated $\mathrm{AsO}_{4}$ & Density $\left(\mathrm{g} \mathrm{cm}^{-3}\right)$ \\
\hline Na-As Jarosite ${ }^{a}$ & 1.00 & $2.83 \mathrm{~g} \mathrm{~cm}^{-3}$ \\
\hline $\mathrm{K}-$ As Jarosite ${ }^{\mathrm{b}}$ & 3.80 & $2.89 \mathrm{~g} \mathrm{~cm}^{-3}$ \\
\hline $\mathrm{Pb}$-As Beudantite ${ }^{\mathrm{c}}$ & 3.24 & $3.03 \mathrm{~g} \mathrm{~cm}^{-3}$ \\
\hline $\mathrm{NH}_{4}-$ As Jarosite d & 4.10 & $2.72 \mathrm{~g} \mathrm{~cm}^{-3}$ \\
\hline $\mathrm{NH}_{4}-\mathrm{Ag}$ Jarosite e & -- & $2.67 \mathrm{~g} \mathrm{~cm}^{-3}$ \\
\hline
\end{tabular}

a Reyes et al., 2011; b Patiño et al., 2013; c Islas et al., 2013; d This work; e Patiño et al., 2003.

Particle size distribution shows that the main particle size was retained in meshes 400 and 500, with diameters ranging between 25 and 38 microns, and a retained weight percentage of $57.25 \%$ and $22.42 \%$ respectively.

The infrared spectrum of the ammonium-arsenic jarosite is shown in Figure 3, together with the spectrum corresponding to an ammonium jarosite synthesised at similar conditions. Three main differences can be observed in the spectra: the overlapping peaks at 865 and $833 \mathrm{~cm}^{-1}$ (spectrum (a)), corresponding to the As-O asymmetric stretching vibration mode [19] due to the presence of arsenic as the arsenate ion; the sharpness of the band at $3400 \mathrm{~cm}^{-1}$ and the shoulder appearing at around 560 $\mathrm{cm}^{-1}$ (spectrum (b)), due to stretching $(v)$ and out-of-plane bending $(\gamma)$ vibrations, respectively, of the $\mathrm{OH}$ ion. As it was espected, the substitution of sulphate ions by arsenate ions leaded to an increase in the $\mathrm{OH} / \mathrm{H}_{2} \mathrm{O}$ ratio in the structure. The band at $1630 \mathrm{~cm}^{-1}$, corresponding to the bending vibration of water molecules, is very similar in both spectra; however, the results from the TGA analysis, presented in the next section, have shown that the water contents is higher in the ammonium-arsenic jarosite.

The fundamental asymmetric vibrations of the sulphate group are due to the stretching $\left(v_{3}\right)$ and bending $\left(v_{4}\right)$ modes; the symmetric stretching $\left(v_{1}\right)$ and bending $\left(v_{2}\right)$ vibrations could also be observed in the infrared, although as weak or very weak bands [20,21]. Reduction in symmetry in the crystal structure of sulphates such as jarosites will cause the splitting of the asymmetric $\mathrm{v}_{3}, \mathrm{SO}_{4}{ }^{2-}$ bands. Infrared bands for ammonium jarosite have been observed at 1080 and $1200 \mathrm{~cm}^{-1}$ [22]. Accordingly, 
the bands at 1070 and $1186 \mathrm{~cm}^{-1}$ are assigned to the S-O and $\mathrm{S}=\mathrm{O}$ asymmetric $v_{3}$ stretching modes and the band at $625 \mathrm{~cm}^{-1}$ is ascribed to the bending $v_{4} \mathrm{SO}_{4}{ }^{2-}$ mode $[21,23]$. The intense band at $990 \mathrm{~cm}^{-1}$ is attributed to an $\mathrm{OH}^{-}$librational mode [21,22]. In addition, the band observed at $1420 \mathrm{~cm}^{-1}$ corresponds to the $\mathrm{NH}$ bending mode and the bands observed between 500 and $460 \mathrm{~cm}^{-1}$ are assigned to the $\mathrm{Fe}-\mathrm{O}$ covalent bonding [21].

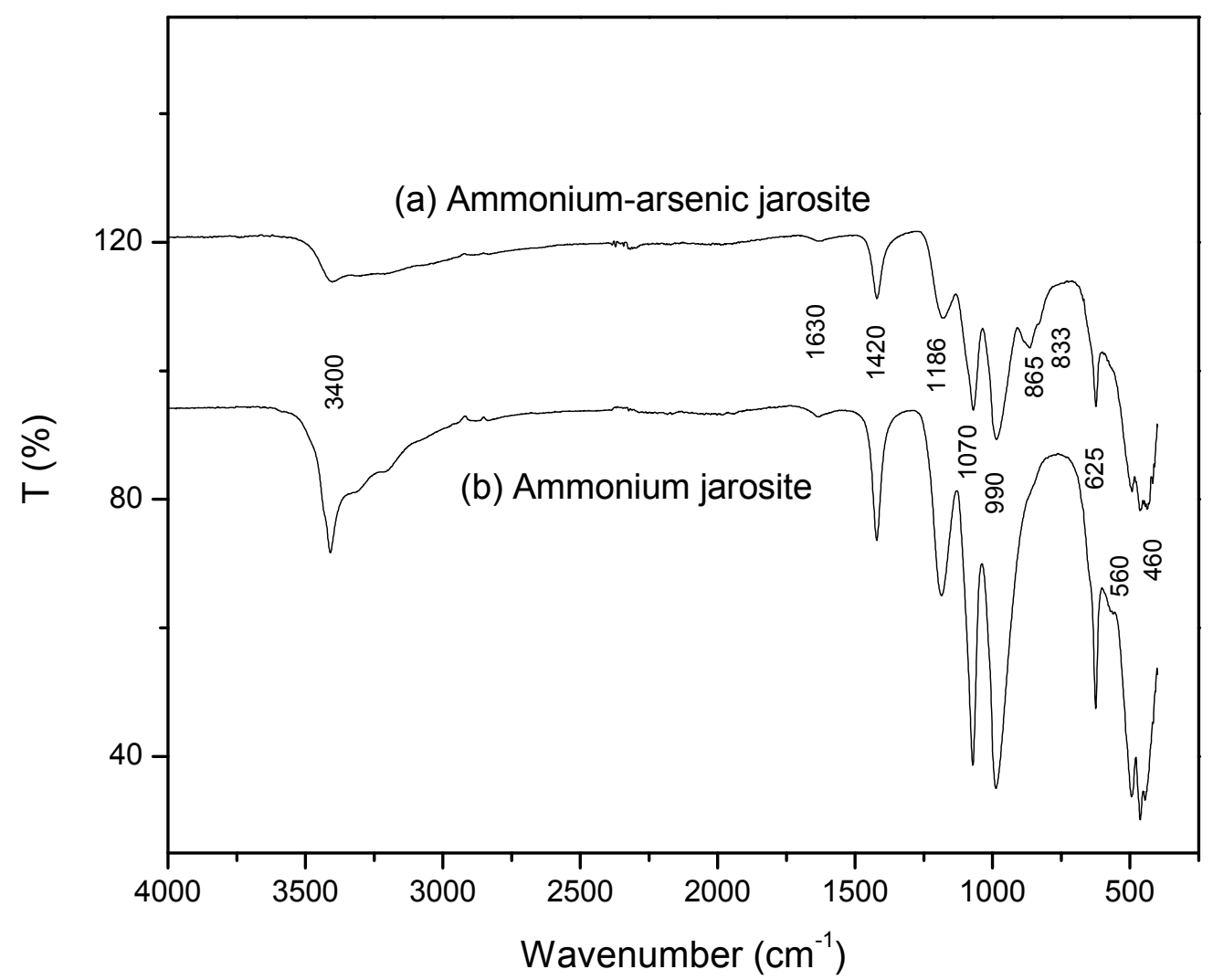

Figure 3. FTIR spectrum of ammonium-arsenic jarosite (a) and ammonium jarosite (b).

\subsection{Thermal decomposition}

The thermogravimetric analysis of the ammonium-arsenic jarosite is shown in Figure 4, together with the corresponding thermogram of an arsenic jarosite synthesised by the same method. As can be seen, the ammonium-arsenic jarosite shows five events of mass loss presents (Figure 4a). The first event, observed between 218 and $365^{\circ} \mathrm{C}$, with a mass loss of $5.83 \%$, could be attributed to the loss of structural and physically adsorbed water. The profile of the curve indicates that desorption is completed at $365^{\circ} \mathrm{C}$ and is followed by the dehydroxylation process in the $365-435^{\circ} \mathrm{C}$ range (second event), with a mass loss of $13.07 \%$. Asumming the total evaporation of $\mathrm{H}_{2} \mathrm{O}$ and $\mathrm{OH}^{-}$contained in the sample $\mathrm{OH} / \mathrm{H}_{2} \mathrm{O}=2.24(\mathrm{w} / \mathrm{w})$ which is less than amoniumm jarosite without arsenic, $\mathrm{OH} / \mathrm{H}_{2} \mathrm{O}=$ $2.87(\mathrm{w} / \mathrm{w})$, thes results were obtained from the percentages showns in Figure $4 \mathrm{~b}$; as expected, the relation $\mathrm{OH} / \mathrm{H}_{2} \mathrm{O}$ in the jarosite with arsenic is less, due to the difference in the chemical valence of the substituent anion, as already mentioned before. The third event, observed between 435 and $540{ }^{\circ} \mathrm{C}$, is attributed to the ammonium evaporation, where a mass loss of $3.1 \mathrm{wt} . \%$ occurs. The transformation of $\mathrm{SO}_{4}$ to $\mathrm{SO}_{2}$ and their evaporation (fourth event) takes place over the $540-670{ }^{\circ} \mathrm{C}$ range, with a $\mathrm{SO}_{4}$, $\mathrm{SO}_{2}$ mass loss of $25.23 \%$. The difference showed a loss of sulfates in comparison to the jarosite without 
arsenic (Figure $4 \mathrm{~b}$ ), as expected with the partial substitution of $\mathrm{AsO}_{4}{ }^{3-}$ by $\mathrm{SO}_{4}$ confirming what was shown in event two. Finally in the fifth event, a minor mass loss $(2.25 \%)$ is observed in the $670-$ $890^{\circ} \mathrm{C}$ range (Figure $4 \mathrm{a}$ ), which is not present in the ammonium jarosite without arsenic (Figure $4 \mathrm{~b}$ ); therefore, as the only difference between the jarosite samples in Figure 4 is the As contents, these loss could be attributed to the transformation of iron arsenate $\left(\mathrm{FeAsO}_{4}\right)$ to iron(III) arsenide (FeAs) [24], since this compound has a high melting point, it is very stable and is easy to form in the presence of iron and arsenic. This is in agreement with the EDS analysis of the thermal decomposition residues of ammonium-arsenic jarosite (Figure 5), that shows the presence of arsenic. In addition, ICP analyzes were performed by the solid decomposition, obtaining a concentration of $20.53 \mathrm{ppm}$, which corresponds to 2.05 weight percent, indicating that it lost 0.15 percent of the total weight of the arsenic, therefore, mass loss of this element is not complete [25-29].
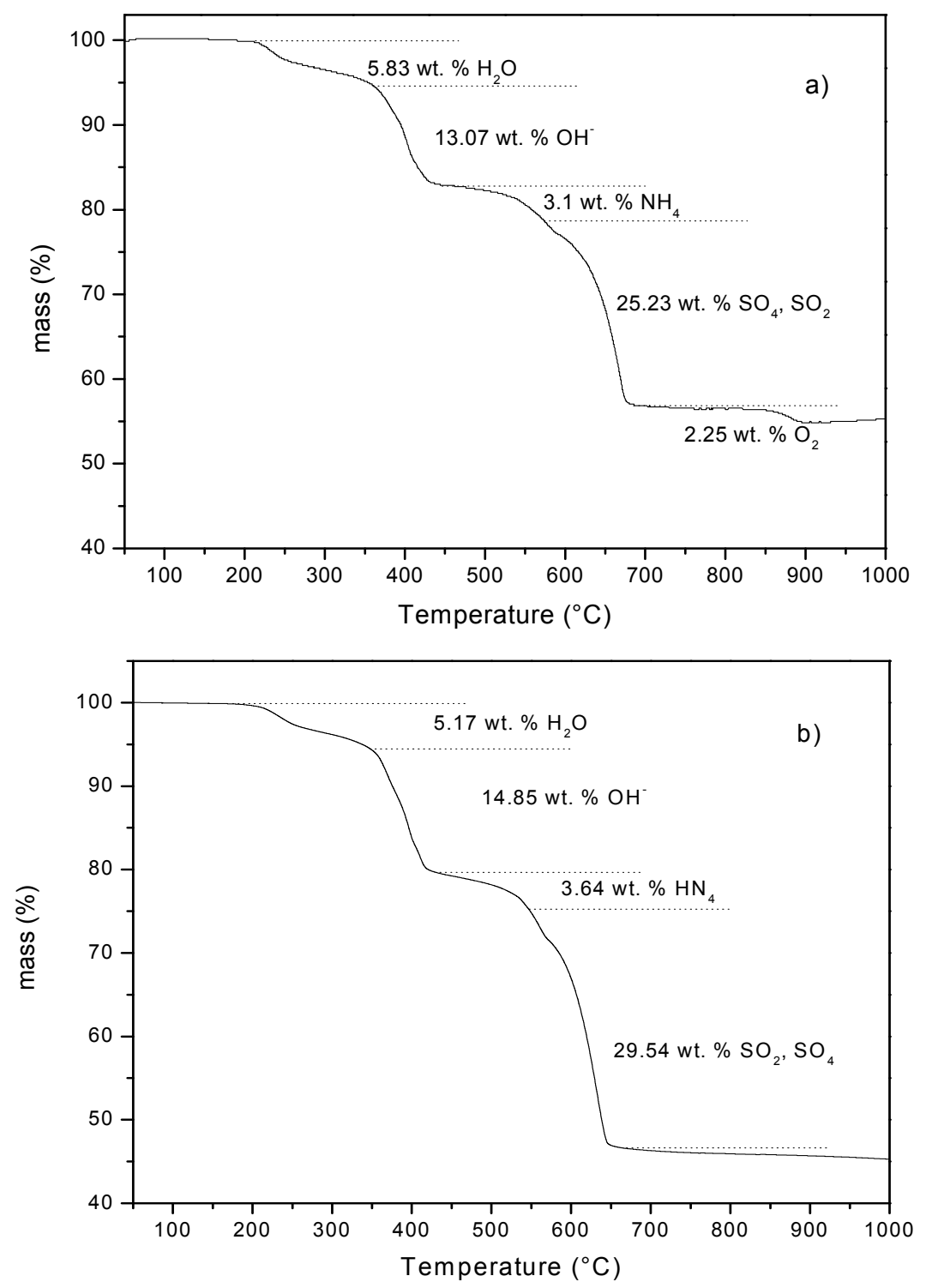

Figure 4. Thermogravimetric analysis curves of ammonium-arsenic jarosite (a) and ammonium jarosite (b). 


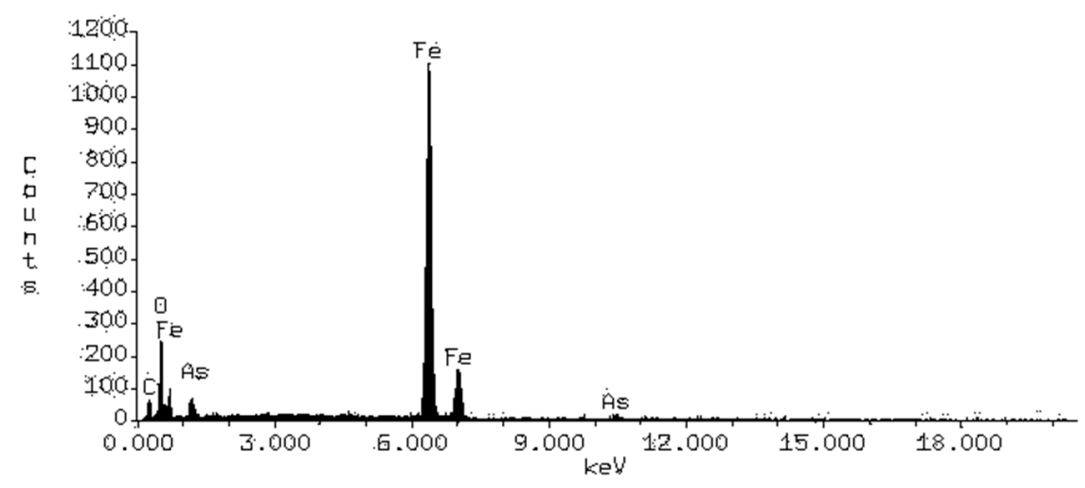

Figure 5. EDS spectrum of the thermal decomposition solids of ammonium-arsenic jarosite $\left(1100^{\circ} \mathrm{C}\right.$ /1 hour).

Then, the reactions occurring during the thermal decomposition process is described by the following equations:

Event 1

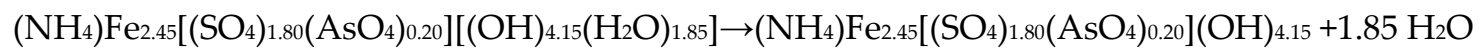

Event 2

$\left(\mathrm{NH}_{4}\right) \mathrm{Fe}_{2.45}\left[\left(\mathrm{SO}_{4}\right)_{1.80}\left(\mathrm{AsO}_{4}\right)_{0.20}\right](\mathrm{OH})_{4.15}+0.24 \mathrm{O}_{2} \rightarrow\left(\mathrm{NH}_{4}\right)(\mathrm{FeO})_{2.45}\left(\mathrm{SO}_{4}\right)_{1.80}\left(\mathrm{AsO}_{4}\right)_{0.20}+2.08 \mathrm{H}_{2} \mathrm{O}$

Event 3

$\left(\mathrm{NH}_{4}\right)(\mathrm{FeO})_{2.45}\left(\mathrm{SO}_{4}\right)_{1.80}\left(\mathrm{AsO}_{4}\right)_{0.20} \rightarrow\left(\mathrm{NH}_{3}\right)^{+}+0.5 \mathrm{H}_{2} \mathrm{O}+0.6 \mathrm{Fe}_{2}\left(\mathrm{SO}_{4}\right)_{3}+0.2 \mathrm{FeAsO}_{4}+0.525 \mathrm{Fe}_{2} \mathrm{O}_{3}+$ $0.188 \mathrm{O}_{2}$

Event 4

$0.6 \mathrm{Fe}_{2}\left(\mathrm{SO}_{4}\right)_{3}+0.2 \mathrm{FeAsO}_{4}+0.525 \mathrm{Fe}_{2} \mathrm{O}_{3} \rightarrow 1.125 \mathrm{Fe}_{2} \mathrm{O}_{3}+1.8 \mathrm{SO}_{2}+0.2 \mathrm{FeAsO}_{4}+0.9 \mathrm{O}_{2}$

Event 5

$1.125 \mathrm{Fe}_{2} \mathrm{O}_{3}+0.2 \mathrm{FeAsO}_{4} \rightarrow 1.125 \mathrm{Fe}_{2} \mathrm{O}_{3}+0.2 \mathrm{FeAs}+0.4 \mathrm{O}_{2}$

$1.125 \mathrm{Fe}_{2} \mathrm{O}_{3}+0.2 \mathrm{FeAs}$

(Final residues)

\subsection{Decomposition in alkaline medium}

The decomposition of ammonium-arsenic jarosite in $\mathrm{NaOH}$ medium has a short induction period. During this period, the jarosite does not react, and therefore, the $\mathrm{SO}_{4}{ }^{2-}$ and $\mathrm{NH}_{4}{ }^{+}$ concentrations are found at negligible levels in the solution (Figure 6). The induction period has been previously observed in the decomposition of lab-synthesized jarosites [13], as well as with jarosites from industrial plants, i.e. ammonium jarosite. The concatenation of $\left[\mathrm{OH}^{-}\right]$ions with the particle 
surface creates active sites until a reaction front is established. The medium ions $\left(\mathrm{OH}^{-}\right.$and $\left.\mathrm{Na}^{+}\right)$ diffuse through this reaction front towards the particle. At the same time, $\mathrm{NH}_{4}{ }^{+}$and $\mathrm{SO}_{4}{ }^{2-}$ ions are released from the particle, diffusing towards the solution. This generates a progressive conversion period, where $\mathrm{SO}_{4}{ }^{2-}$ and $\mathrm{NH}_{4}{ }^{+}$concentrations progressively increase until reaching stabilization, which indicates that the reaction has concluded.

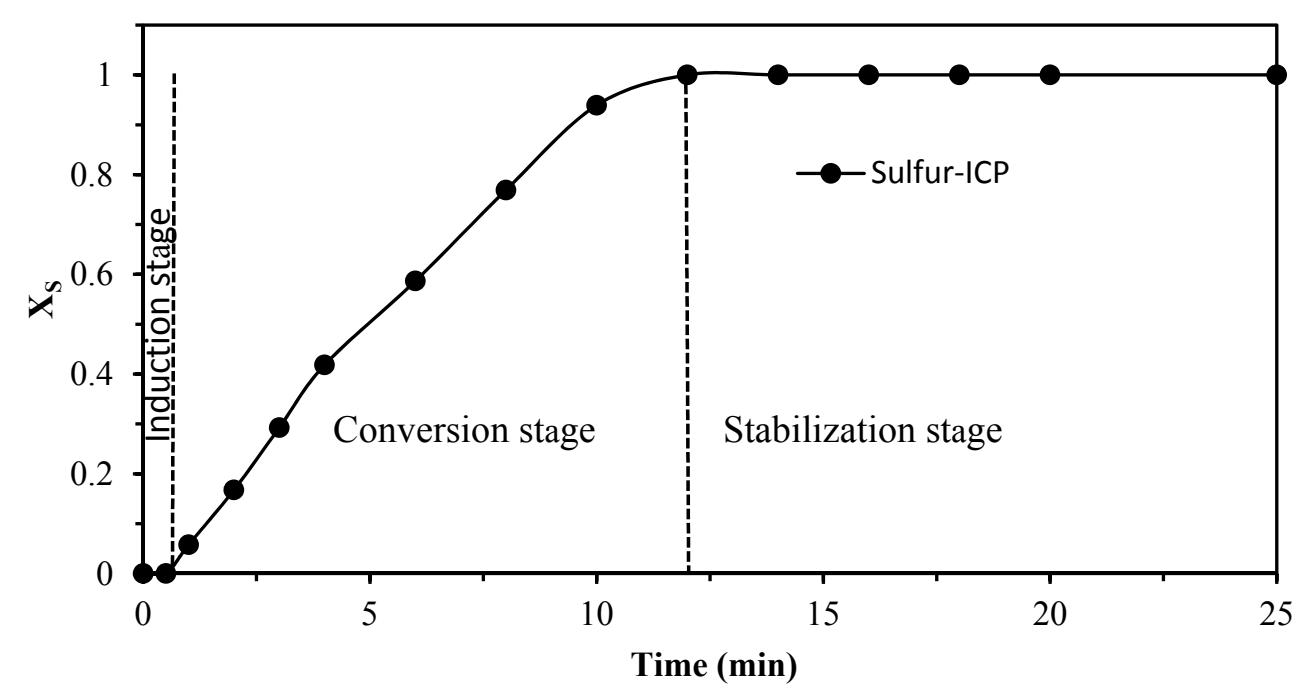

Figure 6. Alkaline decomposition curve of ammonium-arsenic jarosite.

Figure 7 is an image of a partially decomposed particle, showing an unreacted core surrounded by a reaction front, which in turn, is delimited by an amorphous gel of iron hydroxide with arsenic Figure $8 \mathrm{a}$ is the EDS spectrum of the core, showing the typical elements of ammonium-arsenic jarosite. Figure $8 \mathrm{~b}$ is the EDS spectrum of the gel halo, where we can observe how the intensity of sulfur diminishes, while iron and arsenic are still distributed throughout the particle. This indicates that ammonium and sulfur have diffused from the core towards the bulk of the solution. An analysis by ICP decomposition solution was conducted after 50 minutes of reaction and a concentration of $1.08 \mathrm{ppm}$ of arsenic was found, which corresponds to 0.108 percent of the total weight of the compound, so most of the arsenic reains in the particle. 


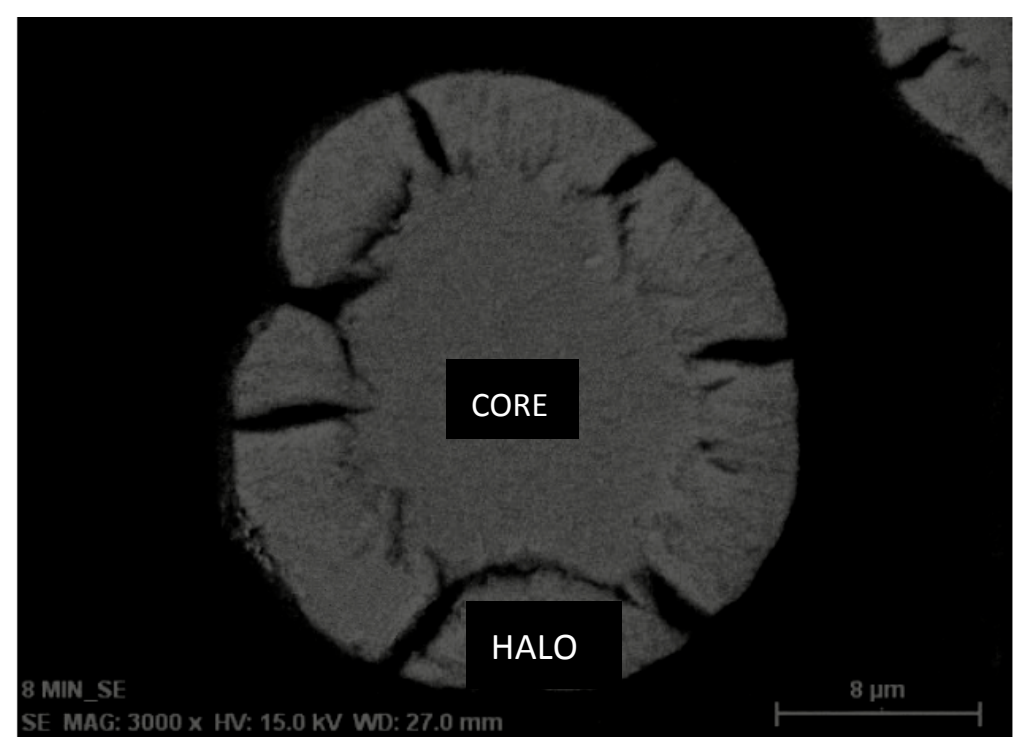

Figure 7. Partially decomposed particle of ammonium-arsenic jarosite.
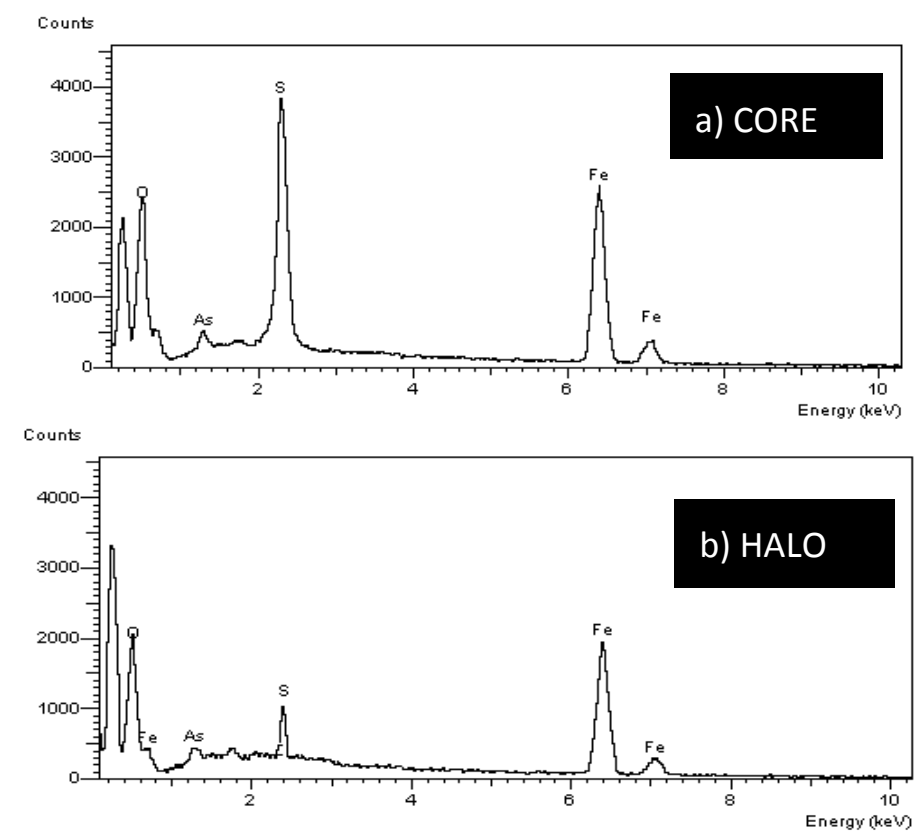

Figure 8. EDS spectra of a partially decomposed particle of ammonium-arsenic jarosite. a) Unreacted core. b) Gel halo.

Figure 9 shows the elemental mappings of partially decomposed particles (Figure 9a). It can be noticed how oxygen, iron and arsenic (Figure 9b, 9c and 9d) are distributed throughout the particle, while sulfur (Figure 9e) are located only in the unreacted core, confirming that arsenic is retained even after the decomposition of ammonium jarosite has ended. The presence of 1.08 ppm of arsenic in the residual solution was determined by ICP, indicating that only $5.4 \%(\mathrm{w} / \mathrm{w})$ of the As present in the jarosite was released at the end of the decomposition process. 


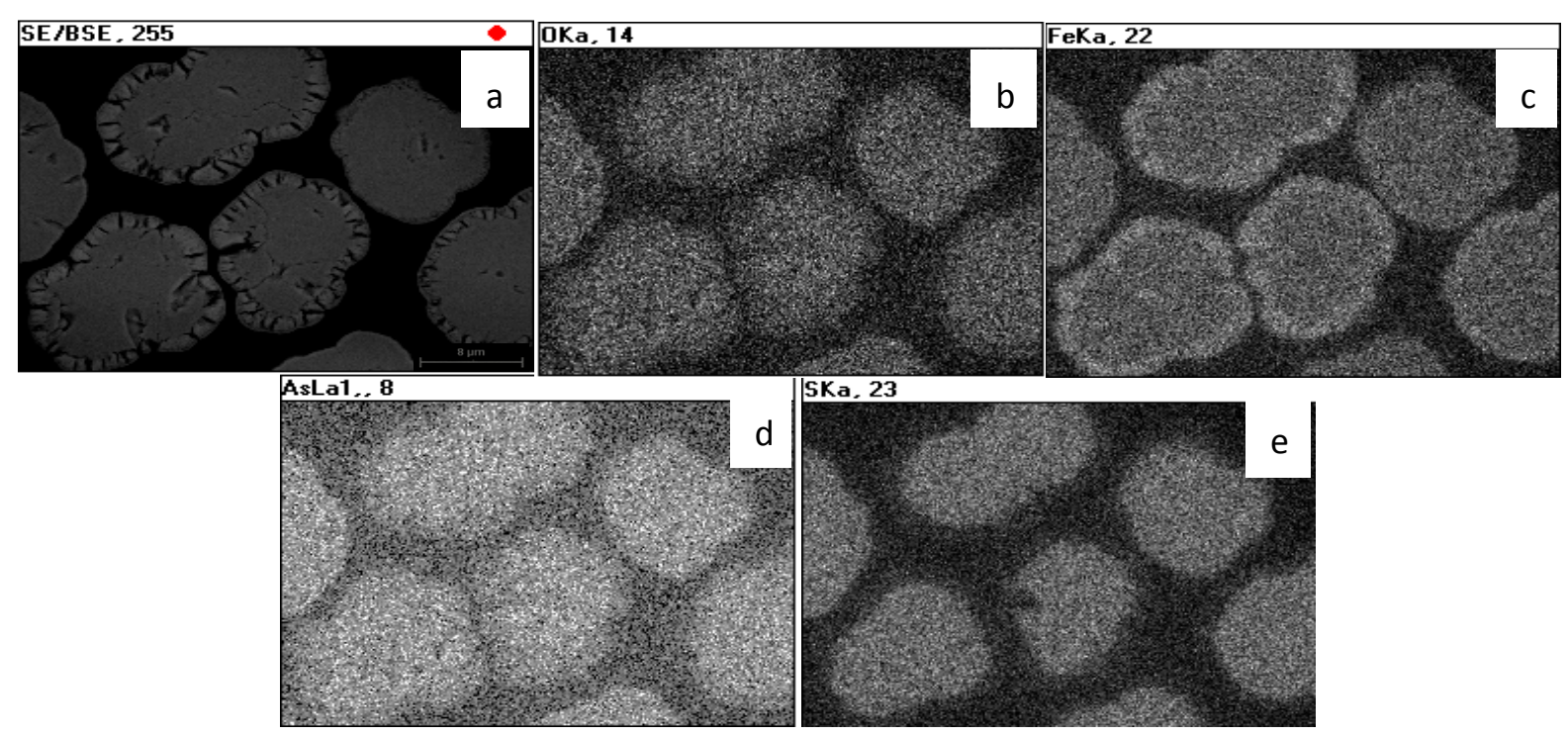

Figure 9. a) Partially decomposed particles. Elemental mapping: b) oxygen, c) iron, d) arsenic and e) sulphur.

Figure 10 shows the $\mathrm{X}$-ray diffraction spectra of the solid residues. As time progresses (from 0 to 30 minutes), the crystallinity of ammonium-arsenic jarosite decreases until it disappears (15 minutes). The result is an amorphous compound made of iron hydroxide with absorbed arsenate. For times subsequent to the total decomposition (15 minutes), the amorphous solid does not evolve into new crystal phases, therefore the stoichiometry of the reaction indicates that sulfate and ammonium ions have diffused towards the solution, while iron and arsenic remain in the decomposition solids in the form of an iron hydroxide gel with absorbed arsenic, as reported by other authors [11]. Accordingly, the stoichiometry of the decomposition reaction in $\mathrm{NaOH}$ medium is the following:

$\left(\mathrm{NH}_{4}\right) \mathrm{Fe}_{2.45}\left[\left(\mathrm{SO}_{4}\right)_{1.80}\left(\mathrm{AsO}_{4}\right)_{0.20}\right]\left[(\mathrm{OH})_{4.15}\left(\mathrm{H}_{2} \mathrm{O}\right)_{1.85}\right]_{(\mathrm{sol})}+3.1 \mathrm{OH}^{-}{ }_{(\mathrm{aq})} \rightarrow \mathrm{NH}_{4}^{+}{ }_{(\mathrm{aq})}+1.8 \mathrm{SO}_{4^{2-}}{ }_{(\mathrm{aq})}+$ $2.45 \mathrm{Fe}(\mathrm{OH}) 3 \cdot 0.20 \mathrm{AsO}_{4}{ }^{3-}(\mathrm{gel})+1.8 \mathrm{H}_{2} \mathrm{O}_{(\mathrm{l})}$ 


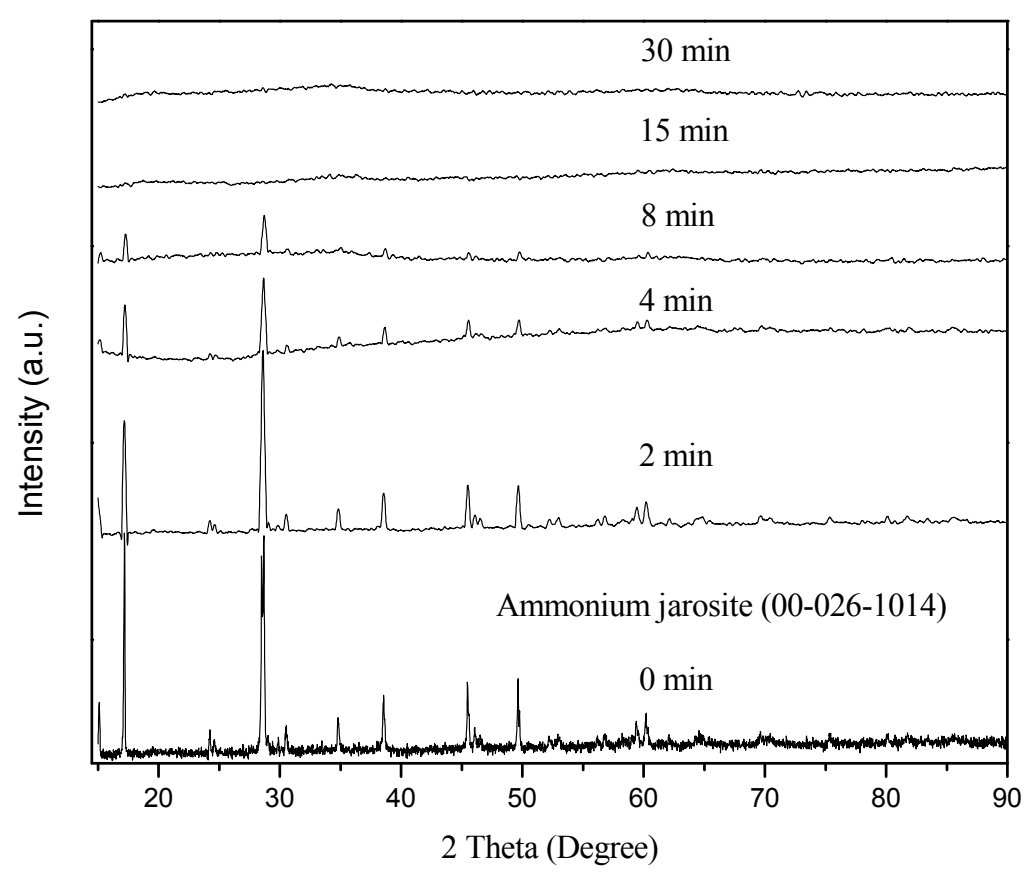

Figure 10. X-ray diffraction spectra of the decomposition reaction of ammonium-arsenic jarosite.

The decomposition solids were exposed to high temperatures to observe their evolution into new crystal phases. At $110^{\circ} \mathrm{C}$ and $400{ }^{\circ} \mathrm{C}$, amorphous solids were obtained (Figure 11). However, at temperatures between $700-1200{ }^{\circ} \mathrm{C}$, the solids evolved into a crystal phase that was identified as hematite $\left(\mathrm{Fe}_{2} \mathrm{O}_{3}\right)$, as observed in Figure 11. An analysis by ICP of the solids of the thermal decomposition was conducted of $1100{ }^{\circ} \mathrm{C}$ and a concentration of $19.48 \mathrm{ppm}$ of arsenic was found, which corresponds to 1.948 percent of the total weight of the compound, so most of the arsenic reains sorbed in the hematite particles in an amorphous compound.

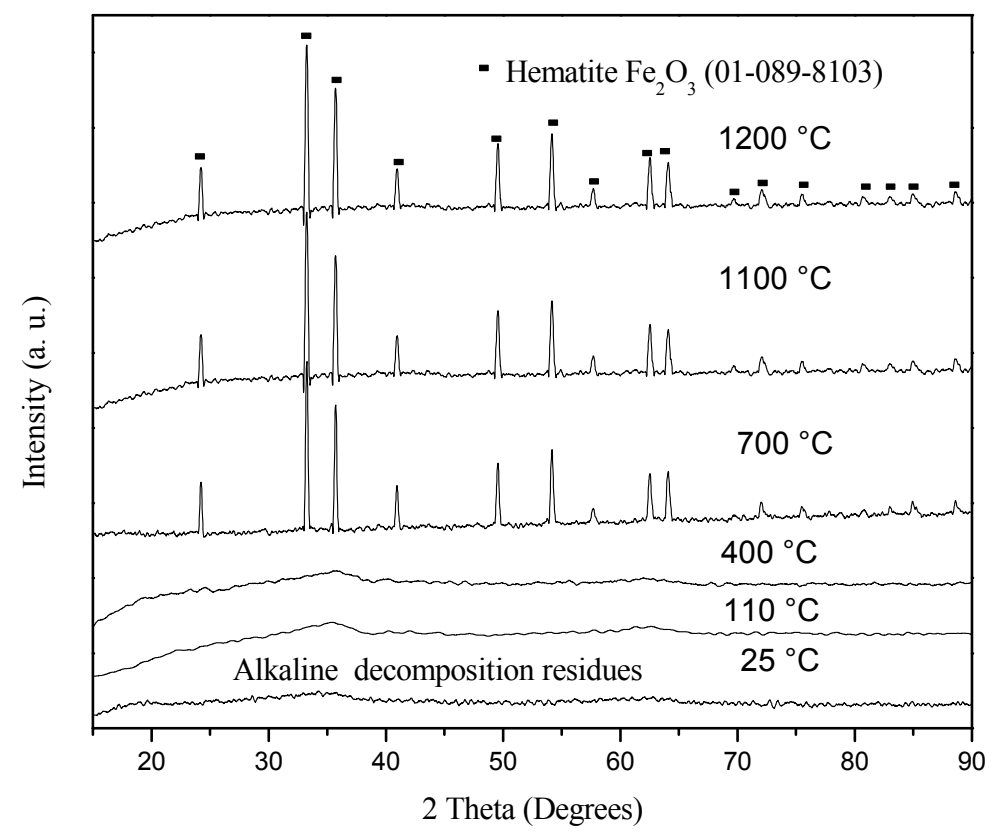

Figure 11. Diffraction spectra of the decomposition solids of ammonium-arsenic jarosite at high temperatures and of the decomposition solids. 


\section{Conclusions}

1) A sample of ammonium-arsenic jarosite was synthesized, with an arsenic content of $2.2 \mathrm{wt} . \%$ (4.1wt. \% as $\mathrm{AsO}_{4}{ }^{3-}$ ). A dark yellow precipitate, made of spherical particles with sizes between 25-38 $\mu \mathrm{m}$, composed of joined rhombohedral microcrystals in a compact structure was obtained. The product's density is $2.72 \mathrm{~g} \mathrm{~cm}^{-3}$. The compound's chemical formula is: $\left(\mathrm{NH}_{4}\right) \mathrm{Fe}_{2.45}$ [( $\left.\left(\mathrm{SO}_{4}\right)_{1.80}\left(\mathrm{AsO}_{4}\right)_{0.20}\right]$ $\left.[(\mathrm{OH}))_{4.15}\left(\mathrm{H}_{2} \mathrm{O}\right){ }_{1.85}\right]$.

2) X-ray diffraction confirmed that the synthesized sample is a jarosite type compound with arsenic. FTIR analysis confirmed the presence of As. TGA analysis confirmed that arsenic is retained at high temperatures $\left(1100^{\circ} \mathrm{C}\right)$.

3) The alkaline decomposition is characterized by an induction period, a progressive conversion period and a stabilization zone. During the progressive conversion period, sulphate and ammonium diffuse from the bulk of the particle into the solution, while arsenic and iron are retained in an amorphous iron hydroxide solid $\left(2.45 \mathrm{Fe}(\mathrm{OH}) \cdot 0.20 \mathrm{AsO}_{4}{ }^{3-}\right)$.

4) The decomposition solids were exposed to high temperatures. It was observed that starting at $700^{\circ} \mathrm{C}$, a new transformation takes place. The result is a new crystal compound that has been identified as hematite. Additionally, the loss of As is not total, even at elevated temperature $\left(890^{\circ} \mathrm{C}\right)$.

5) The ammonium-arsenic jarosite synthesised in this work, even after exposed at elevated temperatures $\left(900^{\circ} \mathrm{C}\right)$ and high alkaline conditions $(\mathrm{pH}=12.9)$, has proven to retain the highest amount of arsenic than similar compounds reported previously. Hence, this type of jarosites have potential application in the control of arsenic and other elements of environmental significance contained in the acid mine drainage.

Acknowledgments: The authors would like to thank to the CONACyT and Iván Reyes would like to thank to the Institute of Metallurgy of the Autonomous University of San Luis Potosi by the Professorship granted.

Author Contributions: Mizraim Flores and Ivan Reyes performed the experiments, Francisco Patiño and Elia Palacios wrote the paper, Victor Flores and Martín Reyes performed the chemical and crystallographic analysis, and Julio Juarez and Thangarasu Pandiyan performed the kinetic studies.

Conflicts of Interest: The authors declare no conflict of interest.

\section{References}

1. Brammer, H. Mitigation of arsenic contamination in irrigated paddy soils in South and South-east Asia. Environ. Int. 2009, 35, 856-863.

2. Asta, M.P.; Cama, J.; Martinez, M.; Giménez, J. Arsenic removal by goethite and jarosite in acidic conditions and its environmental implications. J. Hazard. Mater. 2009, 171, 965-972.

3. Thomas S.Y.; Choong T.G.; Chuah Y.R.: Gregory K.; Azni I. Arsenic toxicity, health hazards and removal techniques from water: an overview. Desalination 2007, 217, 139-166.

4. Desborough, G.A.; Smith, K.S.; Lowers, H.A.; Swayze, G.A.; Hammarstrom, J.M.; Diehl, S.F.; Leinz, R.W.; Driscoll, R.L. Mineralogical and chemical characteristics of some natural jarosites. Geochim. Cosmochim. Acta 2010, 74, 1041-1056.

5. Jambor, J.L. Nomenclature of the alunite supergroup. Can. Mineral. Quart. 1999, 37, 1323-1341.

6. Dutrizac, J.E.; Jambor J.L. The behaviour of arsenic during jarosite precipitation: Arsenic precipitation at 97 ${ }^{\circ} \mathrm{C}$ from sulphate or chloride media. Can. Metall. Quart. 1987, 26, 91-101.

7. Dutrizac, J. E.; Jambor, J.L.; Chen, T.T. The behaviour of arsenic during jarosite precipitation: reactions at $150^{\circ} \mathrm{C}$ and the mechanism of arsenic precipitation. Can. Metall. Quart. 1987, 26, 103-115.

8. Patiño, F.; Viñals, J.; Roca, A.; Núñez, C. Alkaline decomposition-cyanidation kinetics of argentian plumbojarosite. Hydrometallurgy 1994, 34, 279-291. 
9. Patiño, F.; Salinas, E.; Cruells, M.; Roca, A. Alkaline decomposition-cyanidation kinetics of argentian natrojarosite. Hydrometallurgy 1998, 49, 323-336.

10. Patiño, F.; Cruells, M.; Roca, A.; Salinas, E.; Perez, M. Kinetics of alkaline decomposition and cyanidation of argentian ammonium jarosite in lime medium. Hydrometallurgy 2003, 70, 153-161.

11. Patiño, F.; Flores, M.U.; Reyes, I.A.; Reyes, M.; Hernández, J.; Rivera, I.; Juárez, J.C. Alkaline decomposition of synthetic jarosite with arsenic. Geochem. T. 2013, 14 (2), 1-9.

12. Patiño, F.; Reyes, I.A.; Flores, M.U.; Pandiyan, T.; Roca, A.; Reyes, M.; Hernández J. Kinetic modeling and experimental design of the sodium arsenojarosite decomposition in alkaline media: Implications. Hydrometallurgy 2013, 137, 115-125.

13. Reyes, I.A.; Patiño, F.; Rivera, I.; Flores, M.U.; Reyes, M.; Hernández, J. Alkaline reactivity of arsenical natrojarosite. J. Braz. Chem. Soc. 2011, 22, 2260-2267.

14. Dutrizac, J,E.; Kaiman, S. Synthesis and properties of jarosite-type compounds. Can. Mineral. 1976, 14, 151-158.

15. Islas, H.; Patiño, F.; Flores, M.U.; Reyes, I.A.; Reyes, M.; Hernández, J. Synthesis and Characterization of Beudantite. European Metallurgical Conference, Weimar, Germany June 23-26, 2013; Editor Stephan Eicke, Editor Mareike Hahn, Editorial: GDMB: Weimar, Germany, 2013;

16. Savage, K.S.; Bird, D.K.; O’Day, P.A. Arsenic speciation in synthetic jarosite. Chem. Geol. 2005, $215,473-498$.

17. Hawthorne, F.C.; Krivovichev, S.V.; Burns, P.C. The cristal chemistry of sulfate minerals. In: Alpers, C.N., Jambor, J.L., Nordstrom, D.K. (Eds.), Sulfate Minerals: Crystallography, Geochemistry, and Environmental Significance [libro]. Reviews In Mineralogy and Geochemistry, 2000, 40: 1-112.

18. Kitahama, K.; Kiriyama, R.; Baba, Y. Refinement of the crystal structure of scorodite. Acta Crystallogr. B. 1975, 31: 322-324.

19. Satish, C.B.M.; Samuel, J.T.; Glenn, A.W.; Terry, J.L. Vibrational spectroscopy of functional group chemistry and arsenate coordination. Geochim. Cosmochim. Acta 1998, 62, 3499-3514.

20. Colthup, N.P.; Daly, L.H.; Wiberly, E. Introduction to Infrared and Raman Spectroscopy [libro]. 3rd ed. San Diego, California, USA: Academic Press, 1990.

21. Bishop, J.L.; Murad, E. The visible and infrared spectral properties of jarosite and alunite. Am. Mineral. 2005, 90, 1100-1107.

22. Sasaki, K, Tanaike, O.; Konno, H. Distinction of jarosite-group compounds by Raman Spectroscopy. Can. Mineral. 1998, 36, 1225-1235.

23. Kloprogge, J.T.; Huada, R.; Duong, L.V.; Frost, L.R.; FT-IR and Raman microscopic study at 293 K and 77 $\mathrm{K}$ of Celestine, $\mathrm{SrSO}_{4}$, from the middle Triassic Limestone (Muschelkalk) in Winterswijk. Neth J. Geosci. 2001, 80(2), 41-47.

24. Lide, D.R. Handbook of chemistry and physics [libro]. 89th ed. CRC press: Boston, chapter 4, 68, 2009.

25. Frost, R.L.; Weier, M.L.; Martens W. Thermal decomposition of jarosites of potassium, sodium and lead. J. Therm. Anal. Calorim, 2005, 82, 115-118.

26. Frost, R.L.; Wills, R.A.; Kloprogge, J.T.; Martens, N.W. Thermal decomposition of hydronium jarosite

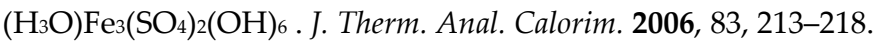

27. Frost, R.L.; Wills, R.A.; Kloprogge, J.T.; Martens, N.W. Thermal decomposition of ammonium jarosite $\left(\mathrm{NH}_{4}\right)_{\mathrm{Fe}}\left(\mathrm{SO}_{4}\right)_{2}(\mathrm{OH})_{6}$. J. Therm. Anal. Calorim. 2006, 84, 489-496.

28. Michelle, J.K.; Hinman, N.W.; Richardson, C.D.; Scott, J.R. Thermal decomposition behavior of potassium and sodium jarosite synthesized in the presence of methylamine and alanine. J. Therm. Anal. Calorim. 2010, $102,23-29$.

29. Alonso, M.; Lopez, A.; López, F.A. A kinetic study of the thermal decomposition of Ammoniojarosite. J. Mat. Sci. 1998, 33, 5821-5825.

(C) 2016 by the authors; licensee Preprints, Basel, Switzerland. This article is an open access article distributed under the terms and conditions of the Creative Commons by Attribution (CC-BY) license (http://creativecommons.org/licenses/by/4.0/). 